\title{
A "Slide Rule" to Adjust Insulin Dose Using Trend Arrows in Adults with Type 1 Diabetes: Test in Silico and in Real Life
}

\author{
Daniela Bruttomesso (D) - Federico Boscari - Giuseppe Lepore • \\ Giulia Noaro · Giacomo Cappon • Angela Girelli · Lutgarda Bozzetto • \\ Andrea Tumminia · Giorgio Grassi · Giovanni Sparacino • \\ Luigi Laviola $\cdot$ Andrea Facchinetti
}

Received: December 18, 2020 / Accepted: January 30, 2021 / Published online: March 16, 2021

(C) The Author(s) 2021

\section{ABSTRACT}

Introduction: In persons with type 1 diabetes (T1D) insulin dosing can be adjusted based on trend arrows derived from continuous glucose monitoring (CGM). We propose a slide rule with narrower blood glucose intervals and more classes of insulin sensitivity than are available in current models.

Methods: The slide rule was tested in silico, in which a meal was simulated in 100 virtual subjects and the insulin bolus was calculated either in the standard way based on the insulinto-carbohydrate ratio and the correction factor or according to the slide rule, following which

D. Bruttomesso $(\square) \cdot$ F. Boscari

Unit of Metabolic Diseases, Department of

Medicine, University of Padova, Padova, Italy

e-mail: daniela.bruttomesso@unipd.it

\section{G. Lepore}

Unit of Endocrine Diseases and Diabetology, ASST

Papa Giovanni XXIII, Bergamo, Italy

G. Noaro · G. Cappon · G. Sparacino ·

A. Facchinetti

Department of Information Engineering, University

of Padova, Padova, Italy

A. Girelli

U.O. Diabetologia ASST Spedali Civili, Brescia, Italy

L. Bozzetto

Department of Clinical Medicine and Surgery,

Federico II University, Napoli, Italy the percentage time spent in range (70-180 $\mathrm{mg} /$ $\left.\mathrm{dl} ; \% \mathrm{~T}_{\mathrm{IR}}\right)$, hypoglycemia $\left(<70 \mathrm{mg} / \mathrm{dl} ; \% \mathrm{~T}_{\mathrm{HYPO}}\right)$, and hyperglycemia (>180 mg/dl; $\% \mathrm{~T}_{\text {HYPER }}$ ) was compared between the methods during the $4 \mathrm{~h}$ after the meal. Slide rule performance was also tested in real life by analyzing the same variables at during the $4 \mathrm{~h}$ postprandial period in 27 individuals with T1D. Only meals starting while the rate of change was at least $1 \mathrm{mg} / \mathrm{dl}$ per minute (increasing or decreasing) were considered for analysis.

Results: In silico, when the preprandial trend arrow was increasing, our slide rule reduced $\% \mathrm{~T}_{\text {HYPER }}$ and increased $\% \mathrm{~T}_{\mathrm{IR}}(p<0.05)$, whereas when the preprandial trend arrow was decreasing, it reduced $\% \mathrm{~T}_{\text {HYPO }}$ and slightly increased

\author{
A. Tumminia \\ Endocrinology, Department of Clinical and \\ Experimental Medicine, University of Catania, \\ Catania, Italy \\ G. Grassi \\ Department of Endocrinology, Diabetology, and \\ Metabolism, Città della Salute e della Scienza \\ University Hospital, Torino, Italy \\ L. Laviola \\ Section of Internal Medicine, Endocrinology, \\ Andrology and Metabolic Diseases, Department of \\ Emergency and Organ Transplantation, University \\ of Bari Aldo Moro, Bari, Italy
}


$\% \mathrm{~T}_{\text {HYPER }}(p<0.05)$. In real life, our slide rule kept subjects on target for 70.8 and $91.6 \%$ of postprandial time when preprandial trend arrows were increasing or decreasing, respectively.

Conclusion: The proposed slide rule performed well both in silico and in real life, suggesting that it could be safely adopted by individuals with T1D to improve glucose control.

Keywords: Continuous glucose monitoring; Insulin dose adjustment; Slide rule; Trend arrows; Type 1 diabetes

\section{Key Summary Points}

Persons with type 1 diabetes (T1D) wearing continuous glucose monitoring (CGM) devices can use a slide rule to adjust meal insulin dosing based on trend arrows.

We devised a new slide rule with more blood glucose intervals and more classes of insulin sensitivity than existing models and tested it 4 hours after a meal in silico and in real life.

In silico, during a simulated meal, the slide rule proved to be safe and effective, irrespective of pre-meal trend arrow direction. In real life, after a meal, the slide rule kept blood glucose on target for $70.8 \%$ of time when the trend arrow was increasing at meal start and for $91.6 \%$ of time when it was decreasing.

The slide rule performed well, both in silico and in real life, without increasing the risk of hypoglycemia.

\section{DIGITAL FEATURES}

This article is published with digital features, including a summary slide, to facilitate understanding of the article. To view digital features for this article go to https://doi.org/10.6084/ m9.figshare.13663769.

\section{INTRODUCTION}

Frequent glucose monitoring is a prerequisite for tight glycemic control in individuals with diabetes, especially for those on intensive insulin therapy. Thus, the introduction of sensors for continuous glucose monitoring (CGM) is a milestone in diabetes management. Two types of CGM systems are currently available: realtime CGM (rtCGM) and intermittently scanned CGM (isCGM), also called flash glucose monitoring (FGM). While both systems collect glucose readings continuously, rtCGM also transmits the collected data to a reader without any action required from the user. In contrast, FGM collects glucose data continuously but, in order to visualize the data the user must actively scan the sensor with a reader device or via an app on his/her smartphone.

FGM and rtCGM provide information on current and previous glucose levels, glucose trends, and anticipated future glycemic status $[1,2]$. Each of these technologies has its own unique features $[3,4]$. For example, rtCGM can alert users of impending or ongoing low and high glucose values, whereas the first generation of FGM does not; however, the latest version of FGM has been provided with optional low and high glucose alerts. CGM and FGM have been shown to improve blood glucose control and reduce the risk of hypoglycemia in people with type 1 diabetes (T1D) [5-11].

A noted advantage of rtCGM and FGM devices is that based on the glucose readings collected during the last 15-20 min, they provide a trend arrow that indicates both the direction and the rate of change (ROC) of glucose. Thus, the user can forecast his/her glucose levels over the next $15-30 \mathrm{~min}$ if the trend remains steady (Table 1$)[12,13]$.

People with T1D using rtCGM or FGM can rely on trend arrows to make insulin dosing adjustments, both in response to incidental high glucose and when calculating a mealtime bolus. Multiple recommendations have been 
Table 1 Interpretation of trend arrows of different continuous glucose monitoring devices

\begin{tabular}{llllll}
\hline $\begin{array}{llll}\text { Trend arrows } \\
\text { abbott/ }\end{array}$ & $\begin{array}{l}\text { Dexcom } \\
\text { Eversense } \\
\text { device }\end{array}$ & $\begin{array}{l}\text { Medtronic } \\
\text { device }\end{array}$ & $\begin{array}{l}\text { Rate of glucose } \\
\text { change (mg/dl/min) }\end{array}$ & $\begin{array}{l}\text { Mean rate of glucose } \\
\text { change (mg/dl/min) }\end{array}$ & $\begin{array}{l}\text { Anticipated glucose } \\
\text { change in } \mathbf{3 0} \text { min (mg/dl) }\end{array}$ \\
\hline $\mathrm{NA}$ & $\uparrow \uparrow$ & $\uparrow \uparrow \uparrow$ & $>3$ & 3 & +90 \\
$\uparrow$ & $\uparrow$ & $\uparrow \uparrow$ & $>2$ or $2-3$ & 2.5 & +75 \\
$\nearrow$ & $\nearrow$ & $\uparrow$ & $1-2$ & 1.5 & +45 \\
$\rightarrow$ & $\rightarrow$ & $\mathrm{NA}$ & Between +1 and & Not considered & Not considered \\
$\searrow$ & & & -1 & & -45 \\
$\downarrow$ & $\searrow$ & $\downarrow$ & $1-2$ & 1.5 & -75 \\
$\mathrm{NA}$ & $\downarrow$ & $\downarrow \downarrow$ & $>2$ or $2-3$ & 2.5 & -90 \\
\hline
\end{tabular}

a Calculation of the glycemic variation over the next $30 \mathrm{~min}$ is based on the trend arrow. The trend arrows, which are computed using retrospective data from the last 15-20 min, forecast the change in the glucose levels in the following $30 \mathrm{~min}$, providing that the trends do not vary

published about how to respond to trend arrow information [12-18].

Recommendations for the DirecNet Applied Treatment Algorithm [14] suggest changes in insulin dose of $0,10 \%$, or $20 \%$ based on the trend arrow. According to Scheiner [15] and Pettus and Edelman [12], a defined value (25-100 mg/dl) should be added or subtracted to the actual glucose level, depending on the trend arrow, and then the correction rule should be applied, requiring mathematical skills and some level of numeracy by the user. Klonoff and Kerr [16] introduced an easy-to-use addition or subtraction formula to correct the insulin dose by adding or subtracting 1, 1.5 or 2 insulin units for ROC of 1-2, 2-3, and $>3 \mathrm{mg} / \mathrm{dl}$ per minute $(\mathrm{mg} / \mathrm{dl} / \mathrm{min})$, respectively.

Laffel and Aleppo proposed adjustments of the insulin dose based on the insulin sensitivity factor, also defined as the correction factor (CF) $(<25,25$ to $<50,50$ to $<75$, and $\geq 75)$, with differences between children [17] and adults [13]. For persons with T1D (both pediatric and adult subjects) and those with type 2 diabetes (T2D) treated with insulin, Ziegler and colleagues suggested adjustments of the insulin dose based on the insulin sensitivity factor (the same as Laffel and Aleppo $[13,17])$ and baseline glucose levels $(<70 \mathrm{mg} / \mathrm{dl} \quad[<3.9 \mathrm{mmol} / \mathrm{l}]$; $70-180 \mathrm{mg} / \mathrm{dl}$ [3.9-10 mmol/l]; $180-250 \mathrm{mg} / \mathrm{dl}$ [10-13.9 mmol/l]; > $250 \mathrm{mg} / \mathrm{dl} \quad[>13.9 \mathrm{mmol} /$ 1]) [18]. The recommendations proposed by Ziegler et al. [18] are the most complete provided to date.

To better meet the needs of patients with T1D, we modified Ziegler's slide rule, increasing both the number of blood glucose intervals and the classes of insulin sensitivity. Here, we present data on the safety and feasibility of our "modified slide rule" in silico and in real life.

\section{METHODS}

\section{The Slide Rule}

We based our slide rule on the model proposed by Ziegler et al. [18], but considered blood glucose values and the $\mathrm{CF}$ according to narrower intervals. Also, in case of hypoglycemia, we recommended the intake of a defined amount of carbohydrates.

Our procedure was as follows: 
A. If the ROC was between -1 and $+1 \mathrm{mg} / \mathrm{dl} /$ min, blood glucose was considered to be stable (horizontal arrow).

B. Outside the range of -1 and $+1 \mathrm{mg} / \mathrm{dl} /$ min, to calculate predicted blood glucose at $30 \mathrm{~min}$, six rates of change (in $\mathrm{mg} / \mathrm{dl} / \mathrm{min}$ ) were considered: lower than -3 (rounded off to -3 ); -3 to -2 (rounded off to -2.5 ); -2 to -1 (rounded off to -1.5 ); 1-2 (rounded off to 1.5 ); $2-3$ (rounded off to 2.5 ); and $>3$ (rounded off to 3 ).

C. Five classes of insulin sensitivity factor (in $\mathrm{mg} / \mathrm{dl} / \mathrm{U}$ ) were considered: $<30$ (rounded off to 30); 30-40 (rounded off to 35); 41-60 (rounded off to 50); 61-90 (rounded off to 75); and $>90$ (rounded off to 90).

D. For preprandial glucose values between 120 and $180 \mathrm{mg} / \mathrm{dl}$, we calculated the correction dose to add to or subtract from the standard bolus by dividing the predicted blood glucose value by insulin sensitivity.

E. For preprandial glucose values between 70 and $119 \mathrm{mg} / \mathrm{dl}$, the insulin dose to subtract (in case of a decreasing trend arrow) was increased by $0.5 \mathrm{U}$ and the one to add (in case of an increasing trend arrow) was decreased by $0.5 \mathrm{U}$; for values between 181 and $250 \mathrm{mg} / \mathrm{dl}$, the insulin dose was increased (increasing trend arrow) or decreased (decreasing trend arrow) by 0.5 $\mathrm{U}$; and for values $>250 \mathrm{mg} / \mathrm{dl}$, the insulin dose was increased or decreased by $1 \mathrm{U}$ (Table 2). Each dose was rounded off to the nearest half unit.

F. In the presence of hypoglycemia the slide rule suggested the amount of carbohydrates needed for correction (Table 2).

\section{When and How to Use the Slide Rule}

Our slide rule was developed for adults with T1D treated with multiple daily injections (MDI) or continuous subcutaneous insulin infusion (CSII) who are using rapid or ultrarapid acting insulin for meals and corrections and calculating the insulin bolus based on the insulin-to-carbohydrate ratio (ICR) and the CF. The slide rule was intended to optimize insulin dose at mealtime and $4 \mathrm{~h}$ after a meal, on the basis of trend arrows. Individuals with rapidly rising preprandial glucose levels could still administer insulin 15-30 min before eating; those with rapidly falling preprandial glucose levels could administer insulin closer to the meal.

Regardless of the trend arrow displayed, individuals should avoid taking corrective action within the first $2 \mathrm{~h}$ after a meal to avoid insulin stacking. Beyond $4 \mathrm{~h}$ it is assumed that most, if not all, carbohydrates have been absorbed and that there is no active bolus insulin available. In this case, we recommend using our rule for dose adjustment. Similar to Ziegler et al. [18], we recommend that, in the presence of ketones, the maximal correction for a given glucose range be applied, irrespective of trend arrow.

\section{Assessment of Performance of the Slide Rule in an In Silico Clinical Trial}

As a first step in the evaluation of our slide rule, we performed computer simulations on a cohort of virtual subjects, modeled to represent a specific population [19]. Specifically, we used the UVa/Padova T1D Simulator [20], a state-ofthe-art simulation tool which includes a virtual cohort of 100 virtual adult subjects with T1D with mean body weight ( \pm standard deviation [SD]) of $69.7 \pm 12.4 \mathrm{~kg}$, mean total daily insulin of $0.61 \pm 0.18 \mathrm{U} / \mathrm{day} / \mathrm{kg}$, mean carbohydrateto-insulin ratio of $15.9 \pm 5.3 \mathrm{~g} / \mathrm{U}$, and mean fasting plasma glucose of $119.6 \pm 6.7 \mathrm{mg} / \mathrm{dl}$. Each subject underwent multiple single-meal experiments. Simulations started at 1:00 p.m., when the virtual subjects had a lunch of $50 \mathrm{~g}$ of carbohydrates (CHO) and an insulin bolus, computed in the first run of simulations with the standard methodology (based on ICR, CF) and in the second one with the proposed slide rule, and ended at 5:00 p.m. Each subject was studied in multiple scenarios characterized by different preprandial blood glucose concentrations and ROC values at mealtime. In total, 72 different scenarios were created, derived from the combination of six preprandial ROC intervals (i.e., $-2,-1.5,-1,1,1.5,2 \mathrm{mg} / \mathrm{dl} / \mathrm{min}$ ) and 12 preprandial blood glucose intervals (i.e. 


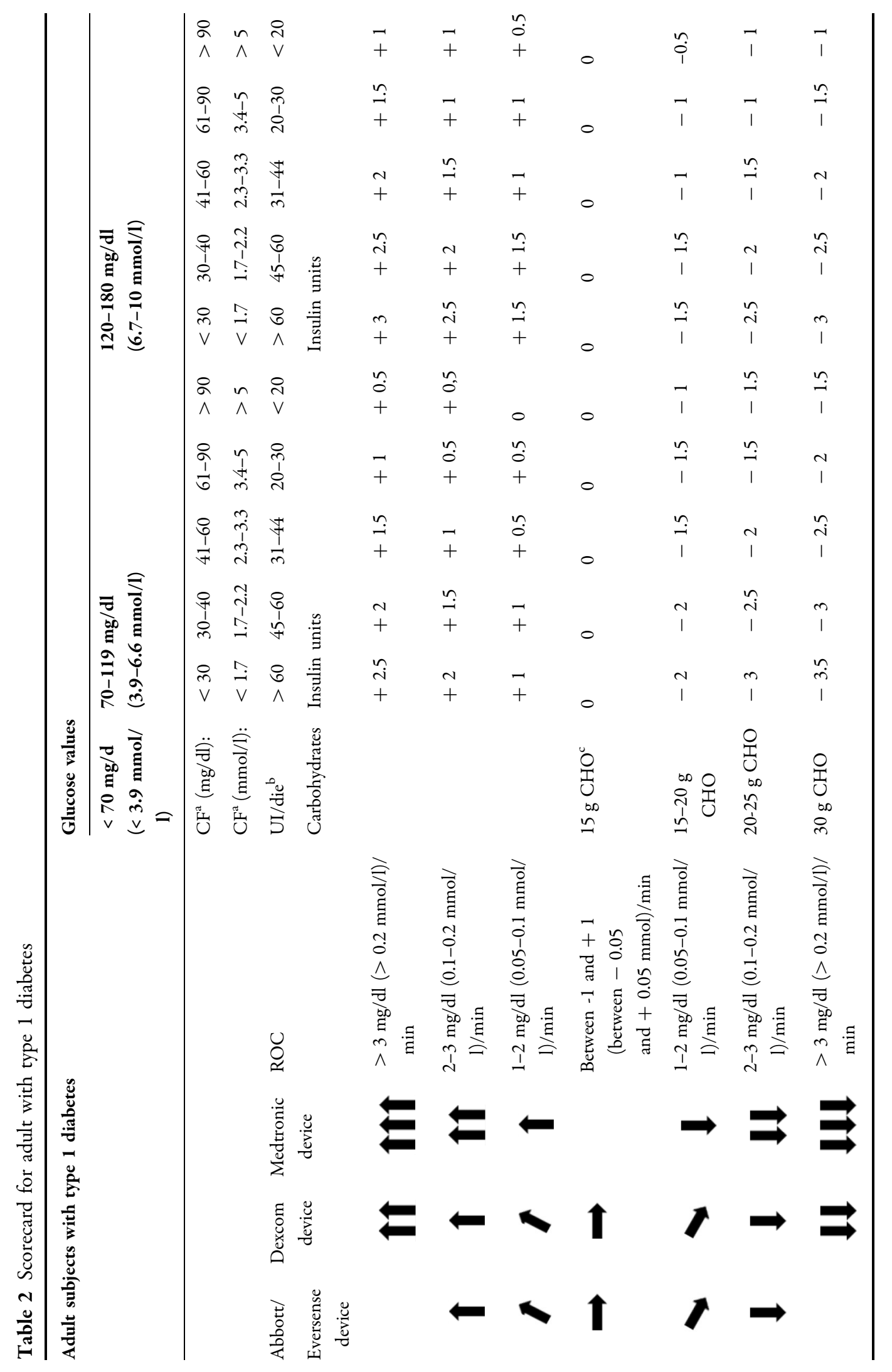




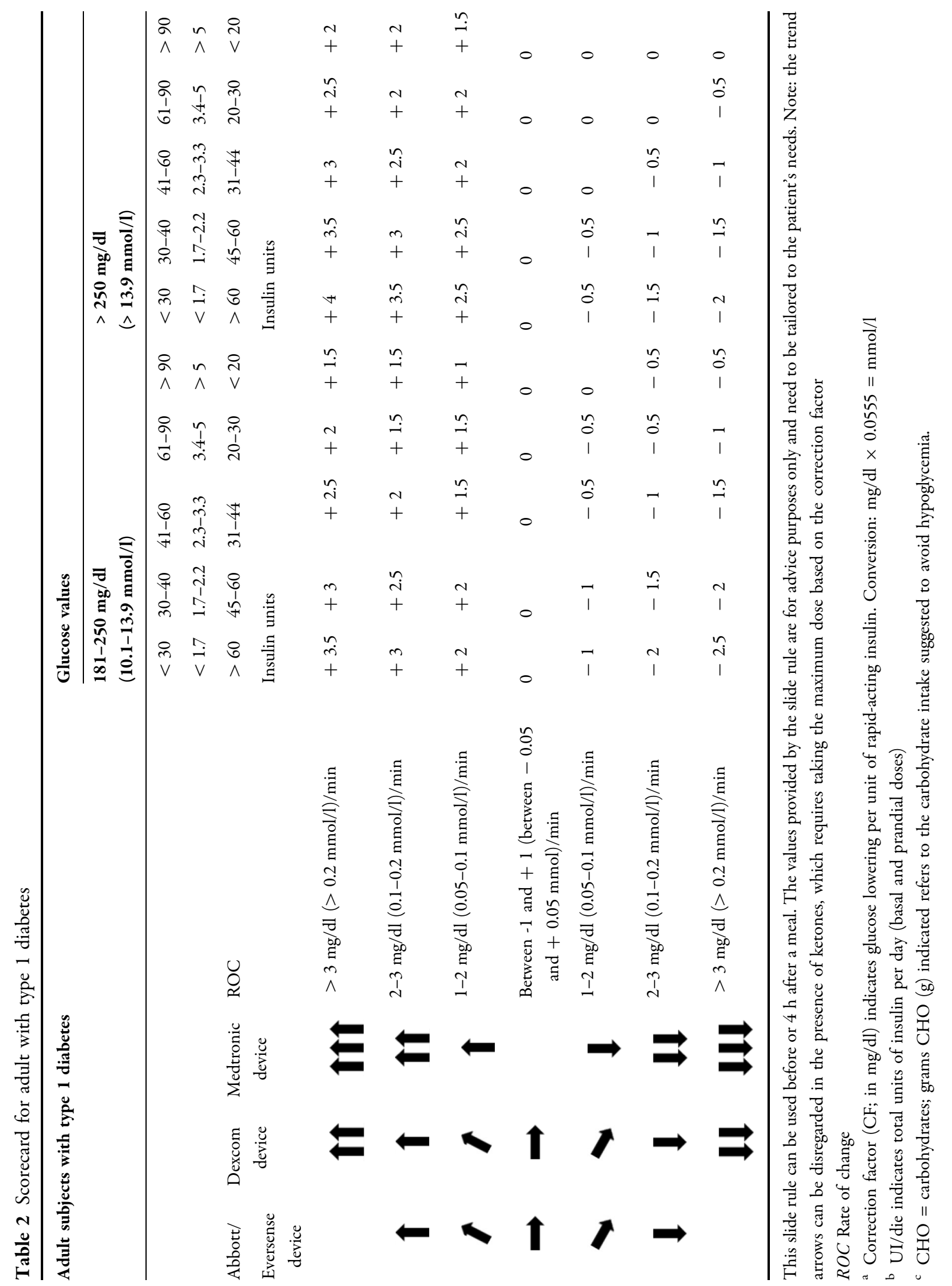


$70,80,90,100,110,120,130,140,150$, $160,170,180 \mathrm{mg} / \mathrm{dl})$.

We did not test scenarios with preprandial ROC between -1 and $+1 \mathrm{mg} / \mathrm{dl} / \mathrm{min}$, since for this range no correction is needed. We also decided not to test scenarios with preprandial ROC values of $>2$ or $<-2 \mathrm{mg} / \mathrm{dl} / \mathrm{min}$, since it is almost impossible for these scenarios to be realistically reproduced in the simulation environment. Additional assumptions were made: (1) simulations were run in a noise-free environment, i.e., without errors in glucose measurements or in $\mathrm{CHO}$ counting; (2) all other potential confounding factors were removed, including patient behavior in making treatment decisions to mitigate hyper/hypoglycemia, changes in individual insulin sensitivity, low or high pre-prandial insulin or $\mathrm{CHO}$ on board; (3) optimal ICR and CF were used; and (4) neither postprandial correction boluses nor hypoglycemia treatments were added.

For each subject and each preprandial blood glucose value and preprandial ROC, we compared the glucose profile obtained using the standard insulin bolus dose with the glucose profile obtained using the insulin bolus computed with the slide rule. Performance was quantified by calculating the percentage of time spent in the range $70-180 \mathrm{mg} / \mathrm{dl}\left(\% \mathrm{~T}_{\mathrm{IR}}\right)$, in hypoglycemia $\left(<70 \mathrm{mg} / \mathrm{dl} ; \% \mathrm{~T}_{\mathrm{HYPO}}\right)$, and in hyperglycemia (>180 mg/dl; \% $\% \mathrm{~T}_{\text {HYPER }}$ ) [21]. Results are reported as the median with the interquartile range (IQR). For the sake of simplicity, results have been aggregated into two scenarios: (1) decreasing ROC and (2) increasing ROC. To assess whether the results related to the use of the slide rule have a statistically significant relationship with those associated with the application of the standard bolus, we performed the Friedman test using a 5\% significance level.

\section{Real-Life Assessment of the Slide Rule Performance}

After the end of the the in silico clinical trial (ISCT), the slide rule was shown, as part of the periodical patient education, to each adult outpatient with T1D under CGM (rtCGM or FGM) visiting any of the respective medical centers from October 2019 to March 2020. We excluded pregnant women and individuals wearing a hybrid closed loop system. Some patients who were routinely using only the CF and the insulin-to-carbohydrate ratio (I:CHO) to determine the standard insulin bolus dose but who were aware of the meaning of the trend arrows decided to test this slide rule to calculate insulin dose according to the slide rule. During the following outpatient visit we realized that 27 subjects had been using the slide rule for at least 2 weeks and had kept a log with $\mathrm{CHO}$, premeal sensor glucose (SG) values, self-monitoring of blood glucose (SMBG) data (when indicated), trend arrow, and insulin doses.

We evaluated only meals with a correct estimate of standard bolus, ROC $\geq 1 \mathrm{mg} / \mathrm{dl} / \mathrm{min}$ and $\leq-1 \mathrm{mg} / \mathrm{dl} / \mathrm{min}$, and no need of correction through boluses or snacks during the $4 \mathrm{~h}$ after mealtime. For each extracted CGM profile, $\% \mathrm{~T}_{\text {HYPER }}, \% \mathrm{~T}_{\mathrm{HYPO}}, \% \mathrm{~T}_{\mathrm{IR}}$ were computed in the 4-h postprandial time-window. We reported the results as two scenarios: (1) increasing ROC only and (2) decreasing ROC only. Finally, for each scenario, we computed $\% \mathrm{~T}_{\mathrm{HYPER}}, \% \mathrm{~T}_{\mathrm{HYPO}}$, and $\% \mathrm{~T}_{\mathrm{IR}}$ considering three different time intervals: (1) from mealtime to $4 \mathrm{~h}$ after the meal; (2) from mealtime to $2 \mathrm{~h}$ after the meal; and (3) from 2 to $4 \mathrm{~h}$ after the meal, hereafter referred to as $\mathrm{T}_{0-4}$, $\mathrm{T}_{0-2}$, and $\mathrm{T}_{2-4}$ respectively. Analysis of $\mathrm{T}_{0-4}$ helps understand if the meal bolus was accurate. To evaluate bolus effect early or late after the meal, we considered the $0-2 \mathrm{~h}$ and $2-4 \mathrm{~h}$ postmeal intervals, respectively.

Data are reported as the median with the IQR.

\section{Compliance with Ethics Guidelines}

The study was performed in accordance with the Helsinki Declaration of 1964, and its later amendments, and was in agreement with national regulations. The study was conceived as a retrospective data collection, and all subjects provided written informed consent to the reuse of clinical data for research purposes. Ethical notification was provided to the ethical committee of the University Hospital of Padova (Comitato Etico per la Sperimentazione Clinica 
Table 3 Results obtained in the virtual cohort for increasing ROC and decreasing ROC

\begin{tabular}{llll}
\hline ROC & Metric & Slide rule & Standard bolus \\
\hline Increasing ROC & $\% \mathrm{~T}_{\text {HYPER }}$ & $44.39^{*}[34.85-54.14]$ & $51.03[41.49-62.65]$ \\
& $\% \mathrm{~T}_{\mathrm{IR}}$ & $54.36^{*}[45.22-66.32]$ & $48.96[37.34-58.50]$ \\
& $\% \mathrm{~T}_{\text {HYPO }}$ & $0.00[0.00-0.00]$ & $0.00[0.00-0.00]$ \\
Decreasing ROC & $\% \mathrm{~T}_{\text {HYPER }}$ & $0.00^{*}[0.00-28.22]$ & $0.00[0.00-16.18]$ \\
& $\% \mathrm{~T}_{\mathrm{IR}}$ & $83.40[65.97-100.00]$ & $87.55[72.40-100.00]$ \\
& $\% \mathrm{~T}_{\text {HYPO }}$ & $0.00^{*}[0.00-1.24]$ & $0.00[0.00-11.20]$ \\
\hline
\end{tabular}

Values in table are presented as the median [interquartile range]. The statistical significance between the twoscenarios and for each metric was evaluated

$\% T_{H Y P E R}$ Percentage of time spent in hyperglycemia $(>180 \mathrm{mg} / \mathrm{dl}), \% T_{I R}$ percentage of time spent in range $70-180 \mathrm{mg} / \mathrm{dl}$, $\% T_{\text {HYPO }}$ percentage of time spent in hypoglycemia $(<70 \mathrm{mg} / \mathrm{dl}$ ), ROC (rate of change)

${ }^{*}$ Statistically significant at $p<0.05$ compared to the corresponding value obtained with the standard bolus

della provincia di Padova, CESC, 15n/AO/20), and the study was approved. The ethics committees of the other participating centers were not notified because it was not required for retrospective studies.

\section{RESULTS}

\section{In Silico Clinical Trial}

In the increasing ROC scenario, using the slide rule, $\% \mathrm{~T}_{\text {HYPER }}$ decreased (44.39 vs. $51.03 \%$, $p<0.05)$ and $\% \mathrm{~T}_{\mathrm{IR}}$ increased (54.36 vs. $48.96 \%$, $p<0.05$ ) (Table 3). No hypoglycemic events were associated with the increased insulin dosage suggested by the slide rule. In the decreasing ROC scenario, there was no change in median values. However, considering the 75th percentile of $\% \mathrm{~T}_{\mathrm{HYPO}}$ and $\% \mathrm{~T}_{\mathrm{HYPER}}$, using the slide rule $\% \mathrm{~T}_{\mathrm{HYPO}}$ decreased (from 11.20 to $1.24 \%, p<0.05$ ) while $\% \mathrm{~T}_{\text {HYPER }}$ increased (from 16.18 to $28.22 \%, p<0.05)$. Overall, the slide rule reduced the risk of hypoglycemia $(p<0.05)$ at the expense of a small increase of $\% \mathrm{~T}_{\text {HYPER }}$ $(p<0.05)$.

\section{Real-Life Use}

Among the 35 patients presented with the slide rule, 27 decided to test it. Of these 27 patients, 16 were male, mean ( \pm SD) age was
$49.3 \pm 13.3$ years, mean duration of diabetes was $27.7 \pm 13.3$ years, and mean glycated hemoglobin (HbA1c) was $55.7 \pm 6.9$ $\mathrm{mmol} / \mathrm{mol}(7.2 \pm 2.8 \%)$. Nine and 18 patients were on MDI and CSII, respectively. Seven patients used an ultrarapid insulin analog and 20 used a rapid insulin analog. Fourteen subjects used a FGM device (Freestyle Libre; Abbott Laboratories, Chicago, IL, USA), 13 used a rtCGM device (2 Eversense [Senseonics, Germantown, MD, USA]; 3 Guardian [Medtronic plc, Fridley, MN, USA]; 8 Dexcom G5 or G6 [DexCom Inc., San Diego, CA, USA]).

The slide rule was used for a mean $( \pm S D)$ of $13.4 \pm 6.4$ days.

Of all meals, only 172 were preceded by a increasing or decreasing arrow. Of these, 64 were not considered in the analysis because the standard insulin bolus had been calculated erroneously or meal composition had not been recorded. Consequently, the final dataset comprised data from 108 meals, 52 with increasing and 56 with decreasing ROC.

In $85 \%$ of cases, the increasing ROC ranged between 1 and $2 \mathrm{mg} / \mathrm{dl} / \mathrm{min}, 13 \%$ ranged between 2 and $3 \mathrm{mg} / \mathrm{dl} / \mathrm{min}$, and the remaining $2 \%$ had values $>3 \mathrm{mg} / \mathrm{dl} / \mathrm{min}$. With regard to the decreasing ROC, $93 \%$ of the values ranged between 1 and $2 \mathrm{mg} / \mathrm{dl} / \mathrm{min}$, while $7 \%$ ranged from 2 to $3 \mathrm{mg} / \mathrm{dl} / \mathrm{min}$.

For the $5 \%$ of meals initiated with sensor glucose (SG) readings of $<70 \mathrm{mg} / \mathrm{dl}, 66 \%$ of the 
Table 4 Results obtained from real-life use of slide rule in the two scenarios: increasing ROC only and decreasing ROC only

\begin{tabular}{lllll}
\hline & Metric & $\mathbf{T}_{\mathbf{0}-\mathbf{4}}$ & $\mathbf{T}_{\mathbf{0 - 2}}$ & $\mathbf{T}_{\mathbf{2}-\mathbf{4}}$ \\
\hline Increasing ROC & $\% \mathrm{~T}_{\text {HYPER }}$ & $27.08[8.33-61.46]$ & $45.83[0-77.08]$ & $0[0-56.25]$ \\
& $\% \mathrm{~T}_{\text {IR }}$ & $70.83[38.54-88.54]$ & $54.17[22.92-100]$ & $83.33[43.75-100]$ \\
& $\% \mathrm{~T}_{\text {HYPO }}$ & $0[0-0]$ & $0[0-0]$ & $0[0-0]$ \\
Decreasing ROC & $\% \mathrm{~T}_{\text {HYPER }}$ & $1.04[0-26.04]$ & $0[0-20.83]$ & $0[0-43.75]$ \\
& $\% \mathrm{~T}_{\text {IR }}$ & $91.67[69.79-100]$ & $97.92[72.92-100]$ & $100[56.25-100]$ \\
& $\% \mathrm{~T}_{\text {HYPO }}$ & $0[0-0]$ & $0[0-0]$ & $0[0-0]$ \\
\hline
\end{tabular}

Median [interquartile ranges] are shown for $\% \mathrm{~T}_{\mathrm{HYPER}}, \% \mathrm{~T}_{\mathrm{HYPO}}, \% \mathrm{~T}_{\mathrm{IR}}$, evaluated from mealtime to $4 \mathrm{~h}$ after the meal $\left(\mathrm{T}_{0-4}\right)$ from mealtime to $2 \mathrm{~h}$ after the meal $\left(\mathrm{T}_{0-2}\right)$, and from 2 to $4 \mathrm{~h}$ after the meal $\left(\mathrm{T}_{2-4}\right)$

patients started with SG in the euglycemic range, and $27 \%$ started with SG between 180 and $262 \mathrm{mg} / \mathrm{dl}$. When the preprandial SG was $<$ $70 \mathrm{mg} / \mathrm{dl}$, the patients performed a SMBG. In all of these cases, the glucose levels turned out to be $>70 \mathrm{mg} / \mathrm{dl}$, and the patients calculated the insulin bolus according to the slide rule, on the basis of the SMBG readings.

The median values, together with the IQR of $\% \mathrm{~T}_{\mathrm{HYPER}}, \% \mathrm{~T}_{\mathrm{IR}}$, and $\% \mathrm{~T}_{\mathrm{HYPO}}$ are reported in Table 4 . In the increasing ROC scenario, $\% \mathrm{~T}_{\mathrm{HY}}$ PER was 45.8 (IQR 0-77.0) during $\mathrm{T}_{0-2}$, decreasing to 0.0 (IQR 0.0-56.3) during $\mathrm{T}_{2-4}$. We obtained a $\% \mathrm{~T}_{\mathrm{IR}}$ of 54.1 (IQR 22.9-100.0) during $\mathrm{T}_{0-2}$ that reached 83.3 (IQR 43.7-100.0) during $\mathrm{T}_{2-4}$. The median $\% \mathrm{~T}_{\mathrm{HYPO}}$ and its IQR were zero for all the time intervals analyzed.

Regarding the decreasing ROC scenario, $\% \mathrm{~T}_{\mathrm{IR}}$ was 97.9 (IQR 72.9-100) during $\mathrm{T}_{0-2}$ while the median values of $\% \mathrm{~T}_{\mathrm{HYPO}}$ and $\% \mathrm{~T}_{\mathrm{HYPER}}$ were both 0 . During $\mathrm{T}_{2-4}$, the median $\% \mathrm{~T}_{\mathrm{HYPO}}$ and $\% \mathrm{~T}_{\text {HYPER }}$ were also both equal to 0 , reaching a median $\% \mathrm{~T}_{\mathrm{IR}}$ of 100 . In general, considering the $\mathrm{T}_{0-4}$ interval in both the increasing and decreasing ROC scenarios, the median $\% \mathrm{~T}_{\mathrm{IR}}$ was 70.8 and 91.6, respectively.

\section{DISCUSSION}

Trend arrows are part of the information provided by glucose sensors, but uniform rules on how to modify insulin dosage based on arrow direction are lacking. Based upon a previous model [18], we developed a slide rule with narrower intervals of preprandial blood glucose and sharper correction factors. We then tested the slide rule in adult individuals with T1D in silico and in real life.

The ISCT showed that the slide rule is efficient and safe, a finding supported by the reallife study. With increasing arrows before meals, our slide rule suggested increasing the insulin dose (calculated according to ICR and CF) by an amount that did not increase the risk of hypoglycemia but kept patients on target for $70 \%$ of the first $4 \mathrm{~h}$ following the meal and for $83 \%$ of the time in the time interval between 2 and $4 \mathrm{~h}$ after the meal. A relatively inferior performance during the first 2 hours after the meal (54\%) was probably due to the preprandial SG often being in the hyperglycemic range, suggests that our slide rule can be further refined.

The slide rule also performed well with decreasing arrows since it advised reducing the insulin dose by an amount that decreased the risk of hypoglycemia without increasing glucose levels (91\% of time in target range during $0-4 \mathrm{~h}$ after the meal and $100 \%$ in the $2-4 \mathrm{~h}$ after the meal).

Existing slide rulers are based on personal experience of the authors of various studies $[13,18]$. To our knowledge, this is the first time a slide rule has been tested both in silico and in real life under conditions of usual diet and daily activities. Analysis of our real-life data shows that our slide rule is safe at controlling 
postprandial hyperglycemia on the basis of arrow trend.

It is important to note that trend arrows add a layer of complexity to deciding the insulin dose; therefore, in this pilot evaluation we offered the slide rule to subjects comfortable with the use of CGM, proficient at calculating standard bolus, and with good knowledge about their response to meals and physical activity. Individuals wearing a pump with a predictive low glucose suspend feature can still use the slide rule if the glucose trend is rising, while the pump would automatically take care of a falling trend. The slide rule should not be used by subjects wearing a hybrid closed loop, in which insulin infusion rate is automatically changed in response to continuous glucose sensing [22]. The slide rule is not meant to replace standard care in the case of forgotten meal insulin dose, hyperglycemia due to erroneous calculation of food $\mathrm{CHO}$ content, or overcorrection for hypoglycemia with fast-acting carbohydrates.

Our slide rule has been tested in adults with T1D wearing the devices reported in Table 2; thus it should be used only in conjunction with these sensors or with devices in which arrows express the same ROC of blood glucose. The global performance of the devices was good but different sensors may differ in terms of accuracy. In some circumstances, trend arrows may not be in agreement with blood glucose values (i.e., in the presence of very low glucose values or when glucose levels change at a very fast rate), so users should always follow the manufacturer's guidance as to when a capillary glucose measurement may be required.

In our subjects, only a few meals were preceded by up or down arrows, indicating a good metabolic control, in agreement with HbA1c concentration.

ROCs at mealtime were mostly within the range of $1-2 \mathrm{mg} / \mathrm{dl} / \mathrm{min}$ (absolute value). Only $2 \%$ of trend arrows were $>3 \mathrm{mg} / \mathrm{dl} / \mathrm{min}$ (absolute value). Based on clinical experience and a study by Kovatchev et al. [23], the time spent while glucose changes more than $3 \mathrm{mg} / \mathrm{dl}$ per minute is relatively infrequent in the absence of food intake or exercise. Our subjects did not exercise, take snacks, or make corrections within the first $4 \mathrm{~h}$ after the meal.

There are some limitations to this study. The real-life evaluation was retrospective and the number of subjects was small. In addition, our proposed tool is only for adult patients with T1D and cannot be used in its current form by children or individuals with T2D. Finally, and importantly, in this study slide rule performance was not compared with a period in which the slide rule was not used or with other methods of trend arrow use.

\section{CONCLUSION}

In conclusion, we have developed a novel slide rule to guide adult patients with T1D to use trend arrows. The use of the slide rule in both in silico and real- life settings increased the time in range without increasing the risk of hypoglycemia. A randomized control study in everyday life in patients with different level of metabolic control will be necessary to extend the validity of these findings.

\section{ACKNOWLEDGEMENTS}

The authors thank patients for their collaboration.

Funding. No funding or sponsorship was received for this study or publication of this article. Part of this work was supported by MIUR (Italian Minister for Education) under the initiative "Departments of Excellence" (Law 232/2016). The Rapid Service Fee was funded by the authors.

Authorship. All named authors meet the International Committee of Medical Journal Editors (ICMJE) criteria for authorship for this article, take responsibility for the integrity of the work as a whole, and have given their approval for this version to be published.

Authorship Contributions. Daniela Bruttomesso, Federico Boscari, Giuseppe Lepore, Angela Girelli, Lutgarda Bozzetto, Andrea 
Tumminia, Giorgio Grassi developed the slide rule; Daniela Bruttomesso, Federico Boscari, Angela Girelli, and Giuseppe Lepore tested slide rule in real life; Giulia Noaro, Giacomo Cappon, Giovanni Sparacino, and Andrea Facchinetti tested the slide rule in silico and evaluated all results, both in the in silico and real-life settings. Daniela Bruttomesso, Federico Boscari, Giuseppe Lepore, Luigi Laviola, Giulia Noaro, Giacomo Cappon, and Andrea Facchinetti contributed to manuscript preparation. All authors contributed to critical review of the manuscript.

Disclosures. Daniela Bruttomesso, Federico Boscari, Giuseppe Lepore, and Angela Girelli have received lecture fees from Abbott and Roche. Luigi Laviola has received lecture fees or consulting fees from Abbott, Medtronic, and Roche. Andrea Tumminia, Giulia Noaro, Giacomo Cappon, Giovanni Sparacino, Lutgarda Bozzetto, Giorgio Grassi, and Andrea Facchinetti have nothing to disclose.

Compliance with Ethics Guidelines. The study was performed in accordance with the Helsinki Declaration of 1964, and its later amendments, and was in agreement with national regulations. The study was conceived as a retrospective data collection, and all subjects provided written informed consent to the reuse of clinical data for research purposes. Ethical notification was provided to the ethical committee of the University Hospital of Padova (Comitato Etico per la Sperimentazione Clinica della provincia di Padova, CESC, 15n/AO/20), and the study was approved. The ethics committees of the other participating centers were not notified because it was not required for retrospective studies.

Data Availability. The datasets generated during and/or analysed during the current study are available from the corresponding author on reasonable request.

Open Access. This article is licensed under a Creative Commons Attribution-NonCommercial 4.0 International License, which permits any non-commercial use, sharing, adaptation, distribution and reproduction in any medium or format, as long as you give appropriate credit to the original author(s) and the source, provide a link to the Creative Commons licence, and indicate if changes were made. The images or other third party material in this article are included in the article's Creative Commons licence, unless indicated otherwise in a credit line to the material. If material is not included in the article's Creative Commons licence and your intended use is not permitted by statutory regulation or exceeds the permitted use, you will need to obtain permission directly from the copyright holder. To view a copy of this licence, visit http://creativecommons.org/licenses/by$\mathrm{nc} / 4.0 /$.

\section{REFERENCES}

1. Mian Z, Hermayer KL, Jenkins A. Continuous glucose monitoring: review of an innovation in diabetes management. Am J Med Sci. 2019;358:332-9. https://doi.org/10.1016/j.amjms.2019.07.003.

2. Bruttomesso D, Laviola L, Avogaro A, et al. The use of real time continuous glucose monitoring or flash glucose monitoring in the management of diabetes: a consensus view of Italian diabetes experts using the Delphi method. Nutr Metab Cardiovasc Dis. 2019;29(5):421-31. https://doi.org/10.1016/j. numecd.2019.01.018.

3. Cappon G, Vettoretti M, Sparacino G, Facchinetti A. Continuous glucose monitoring sensors for diabetes management: a review of technologies and applications. Diabetes Metab J. 2019;43(4):383-97. https://doi.org/10.4093/dmj.2019.0121.

4. Edelman SV, Argento NB, Pettus J, Hirsch IB. Clinical implications of real-time and intermittently scanned continuous glucose monitoring. Diabetes Care. 2018;41(11):2265-74. https://doi.org/10. 2337/dc18-1150.

5. Juvenile Diabetes Research Foundation Continuous Glucose Monitoring Study Group, Tamborlane WV, Beck RW, et al. Continuous glucose monitoring and intensive treatment of type 1 diabetes. $\mathrm{N}$ Engl J Med. 2008;359(14):1464-76. https://doi.org/10. 1056/NEJMoa0805017.

6. Beck RW, Riddlesworth T, Ruedy K, et al. Effect of continuous glucose monitoring on glycemic control in adults with type 1 diabetes using insulin injections: the DIAMOND randomized clinical trial. 
JAMA. 2017;317(4):371-378. https://doi.org/10. 1001/jama.2016.19975.

7. Lind M, Polonsky W, Hirsch IB, et al. Continuous glucose monitoring vs conventional therapy for glycemic control in adults with type 1 diabetes treated with multiple daily insulin injections: the GOLD randomized clinical trial. JAMA. 2017;317(4):379-87. https://doi.org/10.1001/jama. 2016.19976.

8. Bolinder J, Antuna R, Geelhoed-Duijvestijn P, Kröger J, Weitgasser R. Novel glucose-sensing technology and hypoglycaemia in type 1 diabetes: a multicentre, non-masked, randomised controlled trial. Lancet. 2016;388(10057):2254-63. https://doi. org/10.1016/S0140-6736(16)31535-5.

9. Battelino T, Conget I, Olsen B, et al. The use and efficacy of continuous glucose monitoring in type 1 diabetes treated with insulin pump therapy: a randomised controlled trial. Diabetologia. 2012;55(12): 3155-62. https://doi.org/10.1007/s00125-0122708-9.

10. Tumminia A, Crimi S, Sciacca L, et al. Efficacy of real-time continuous glucose monitoring on glycaemic control and glucose variability in type 1 diabetic patients treated with either insulin pumps or multiple insulin injection therapy: a randomized controlled crossover trial. Diabetes Metab Res Rev. 2015;31(1):61-8. https://doi.org/10.1002/dmrr. 2557.

11. Welsh JB. Role of continuous glucose monitoring in insulin-requiring patients with diabetes. Diabetes Technol Ther. 2018;20(S2):S242-9. https://doi.org/ 10.1089/dia.2018.0100.

12. Pettus J, Edelman SV. Recommendations for using real-time continuous glucose monitoring (rtCGM) data for insulin adjustments in type 1 diabetes. J Diabetes Sci Technol. 2017;11(1):138-47. https:// doi.org/10.1177/1932296816663747.

13. Aleppo G, Laffel LM, Ahmann AJ, et al. A practical approach to using trend arrows on the Dexcom G5 CGM system for the management of adults with diabetes. J Endocr Soc. 2017;1(12):1445-60. https:// doi.org/10.1210/js.2017-00388.

14. Diabetes Research In Children Network (DirecNet) Study Group, Buckingham B, Xing D, et al. Use of the DirecNet applied treatment algorithm (DATA) for diabetes management with a real-time continuous glucose monitor (the FreeStyle Navigator). Pediatr Diabetes. 2008;9(2):142-7. https://doi.org/ 10.1111/j.1399-5448.2007.00301.x.
15. Scheiner G. Practical CGM: improving patient outcomes through continuous glucose monitoring. 4th ed. Alexandria: American Diabetes Association; 2015.

16. Klonoff DC, Kerr D. A simplified approach using rate of change arrows to adjust insulin with realtime continuous glucose monitoring. J Diabetes Sci Technol. 2017;11:1063-9. https://doi.org/10.1177/ 1932296817723260 .

17. Laffel LM, Aleppo G, Buckingham BA, et al. A practical approach to using trend arrows on the Dexcom G5 CGM system to manage children and adolescents with diabetes. J Endocr Soc. 2017;1(12): 1461-76. https://doi.org/10.1210/js.2017-00389.

18. Ziegler R, von Sengbusch S, Kröger J, et al. Therapy adjustments based on trend arrows using continuous glucose monitoring systems. J Diabetes Sci Technol. 2019;13(4):763-73. https://doi.org/10. $1177 / 1932296818822539$.

19. Viceconti M, Cobelli C, Haddad T, Himes A, Kovatchev B, Palmer $\mathrm{M}$. In silico assessment of biomedical products: the conundrum of rare but not so rare events in two case studies. Proc Inst Mech Eng H. 2017;231(5):455-66. https://doi.org/ $10.1177 / 0954411917702931$.

20. Dalla Man C, Micheletto F, Lv D, Breton M, Kovatchev B, Cobelli C. The UVA/PADOVA type 1 diabetes simulator: new features. J Diabetes Sci Technol. 2014;8(1):26-34. https://doi.org/10.1177/ 1932296813514502 .

21. Battelino T, Danne T, Bergenstal RM, et al. Clinical targets for continuous glucose monitoring data interpretation: recommendations from the international consensus on time in range. Diabetes Care. 2019;42(8):1593-603. https://doi.org/10.2337/ dci19-0028.

22. Saunders A, Messer LH, Forlenza GP. MiniMed $670 \mathrm{G}$ hybrid closed loop artificial pancreas system for the treatment of type 1 diabetes mellitus: overview of its safety and efficacy. Expert Rev Med Devices. 2019;16(10):845-53. https://doi.org/10. 1080/17434440.2019.1670639.

23. Kovatchev BP, Clarke WL, Breton M, Brayman K, McCall A. Quantifying temporal glucose variability in diabetes via continuous glucose monitoring: mathematical methods and clinical application. Diabetes Technol Ther. 2005;7(6):849-62. https:// doi.org/10.1089/dia.2005.7.849. 